\section{Os polienos antibióticos}

\author{
MIGUEL A. R. B. CASTANHO*
}

Uma cadeia poliénica consiste num conjunto de ligações duplas e simples alternadas, sem ramificações (sistema de ligações duplas deslocalizadas). As caracteristicas químicas e bioquímicas das moléculas que possuem estas cadeias são frequentemente dominadas pelas caracteristicas deste conjunto de ligações e são designadas, por extensão, polienos. Algumas destas moléculas são antibióticos ${ }^{1}$ [1]. Todos os polienos que são antibióticos naturais, são também macrólidos $^{2}$ (i. e., moléculas anelares de grandes dimensões e bastante funcionalizadas; usualmente moléculas macrociclicas contendo uma ligação éster na estrutura do anel - lactonas). Em todos estes antibióticos é necessário que a estrutura anelar esteja intacta, além da existência do sistema deslocalizado de ligações duplas, para que haja actividade biológica (alterações de permeabilidade em fungos, resultando na libertação de constituintes citoplasmáticos e culminando com a morte celular) [2]. Uma outra característica comum a estes antibióticos é a dualidade da polaridade do anel: uma metade hidrófila, devida à presença dos grupos hidroxilo e outra hidrófoba. Esta dualidade, nalguns casos (e. g. anfotericina B e nistatina, figura 1) pode ser reforçada pela presença de um grupo micosamina. Neste caso os antibióticos tornam-se anfóteros, i. e., possuem um grupo ácido e outro básico.

Quando se iniciaram os estudos sobre estes antibióticos não era ainda discutido o seu mecanismo de acção,

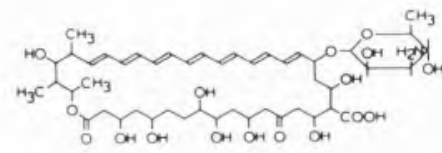

a

Figura 1 - Fórmulas estruturais da anfotericina $B$ (a) e nistanina (b). mas apenas os efeitos tóxicos microbiológicos (anos 60). Admitia-se, então, generalizadamente que todos os antibióticos com polienos tinham o mesmo mecanismo básico de acção [2] $]^{3}$.

Os trabalhos de Lampen et al. (e. g. [3]) e de Kinsky (e.g. [2]) marcaram de forma decisiva 0 entendimento futuro do mecanismo de acção dos antibióticos com polieno. Nestes estudos foi demonstrado que estes antibióticos causam alterações de permeabilidade em fungos e dai se concluiu ser a sua acção ao nivel da membrana citoplasmática. Mais relevante, no entanto, foi a descoberta de que estes antibióticos não possuem actividade bactericida. Por consequência, a membrana celular deve conter um componente de ligação aos antibióticos presente apenas nos microorganismos sensíveis. Sabendo-se, pelos mesmos estudos, que os antibióticos são capazes de interactuar com esteróis (a espectroscopia de absorção assim 0 demonstra) e que a adição de esteróis ao meio de cultura celular diminui a capacidade letal dos antibióticos, foi colocada a hipótese deste componente de ligação ser um esterol (esta é ainda hoje designada "hipótese dos esteróis"). Mas o que deu solidez a esta hipótese foi o facto dos esteróis serem abundantes nas membranas dos fungos e serem extremamente escassos, ou inexistentes, nas das bactérias.

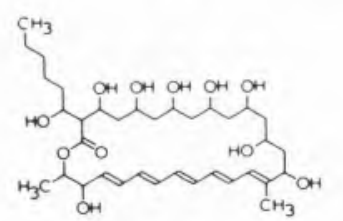

Figura 2 - Filipina III. Este é o componente mais abundante da mistura extraida do microorganismo Streptomyces filipinensis.

A "afinidade" dos diferentes antibióticos para diferentes esteróis estaria assim na base, não só da selectividade, mas também da eficácia dos macrólidos com polienos. Desta forma, por exemplo, a toxicidade da filipina ${ }^{4}$ (um outro polieno antibiótico, figura 2) contra as células de mamíferos estaria explicada

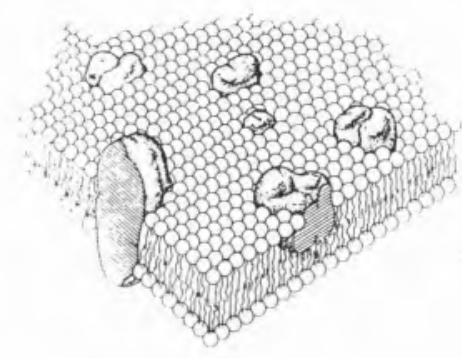

A

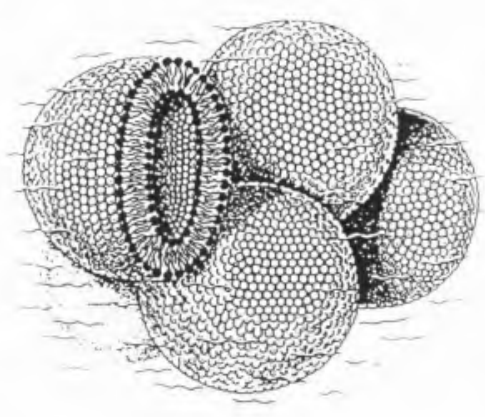

B

Figura 3 - A) Modelo esquemático ilustrando proteinas globulares dissolvidas na matriz lipidica de uma membrana biológica - Modelo do mosaico fluido, de Singer e Nicolson; B) Representaçẫo de vesículos lipídicos, unilamelares e esféricos. Existem outros tipos de vesículos, variando no seu tamanho (em dimensões superiores a geometria esférica não se mantém) e no facto de haver vesículos contidos dentro de outros vesiculos (i.e., serem multilamelares), ou não. Os vesículos multilamelares grandes, são usualmente designados MLV ou lipossomas.

pela capacidade desta para se associar ao colesterol, ao contrário de, por exemplo, a anfotericina B e nistanina, que se ligariam com maior "afinidade" ao ergosterol (portanto, às membranas celulares de fungos) do que ao colesterol (portanto, às membranas celulares dos mamíferos). Esta toxicidade da filipina em relação às células de mamíferos levou a que este antibiótico não tivesse merecido tanta atenção por parte dos investigadores, mais atraídos pelas vantagens clínicas da aplicação terapêutica dos antibióticos do que na descoberta do mecanismo bioquímico da sua acção antibiótica. Com a nistatina e a anfotericina B (comercializada numa mistura com sais biliares, conhecida por «fungizona", que forma uma dispersão em meio aquoso), tal não aconteceu. 
Desde o principio dos anos 60 que a anfotericina B é usada no tratamento de infecções fúngicas pelas suas propriedades fungiestáticas (i. e., retardando 0 crescimento populacional de fungos) e fungicidas contra um grande leque de fungos, dos quais poucos desenvolvem resistência (e.g. [4]).

Mas 0 que permitiu um grande desenvolvimento do estudo e aplicações clínicas da anfotericina B foi o facto de, na generalidade, se obter uma boa correlação entre eficácia do antibiótico in vitro e os resultados clínicos das terapias (e. g. [5]). 0 uso de sistemas modelo (bicamadas de fosfolípidos que simulam as membranas biológicas por consistirem na sua estrutura básica; figura 3) ganha assim um significado particular na elucidação dos mecanismos bioquímicos da acção antibiótica.

Como já indicámos, os resultados obtidos a nível celular levam à hipótese, bem aceite na generalidade, de a acção dos antibióticos com polieno ser 0 aumento da permeabilidade celular e que esta acção depende directamente da natureza dos esteróis presentes na membrana. Consequentemente, tem sido comum o recurso a sistemas modelo de membranas em estudo sobre a acção bioquímica dos antibióticos com polieno, usando os métodos mais diversos. Além disto, a interacção entre estes antibióticos e sistemas modelo de membranas é relevante para o desenvolvimento do uso de, por exemplo, lipossomas (vesículos semelhantes aos esquematizados na figura $3 \mathrm{~b}$, mas multilamelares e de grandes dimensões) como vectores (transportadores) destas drogas, aumentando a sua toxicidade e selectividade.

Desde 0 final dos anos 70 que a maioria dos investigadores recorre a vesículos de fosfolípidos, que possibili-

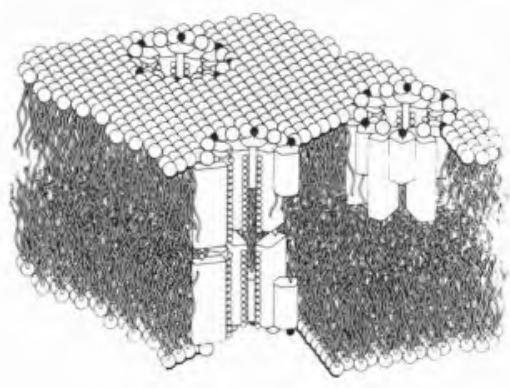

Figura 4 - Representação esquemática do poro formado por moléculas de anfotericina-B e colesterol numa bicamada lipídica. tam a realização de estudos sobre a libertação de componentes encapsulados no seu interior. As células Acholeplasma laidlawii podem ser consideradas um modelo sofisticado, uma vez que o teor da membrana em esteróis e o tipo de esteróis podem ser modificados e controlados por alteração da composição do meio da cultura celular.

A microscopia electrónica, em especial a de crio-fractura ${ }^{5}$, tem sido utilizada por vários grupos que tentam associar determinadas perturbaçōes nas membranas com a natureza da acção do antibiótico e, portanto, do seu mecanismo bioquímico (e.g. [6]). A aplicação desta técnica tem sido feita quer em vesículos, quer em células. No entanto, os estudos espectroscópicos são os que têm elucidado mais profundamente 0 conhecimento da acção antibiótica a nivel molecular. As técnicas ópticas são frequentemente usadas. De entre elas, a fluorescência e o Raman de ressonância destacam-se por produzirem sinais mensuráveis com uma razão sinal/ruido muito satisfatória em sistemas cuja concentração de antibiótico é da ordem de grandeza dos micromolar. Esta é uma característica de extrema importância porque os estudos com membranas artificiais devem usar meios com antibióticos cuja concentraçāo seja cerca de $10^{-6}$, e não $10^{-4} \mathrm{M}$ ou $10^{-3} \mathrm{M}$ como é frequente, que é duas ou três ordens de grandeza superior aos necessários para obter acção tóxica sobre membranas naturais. Só assim os resultados obtidos com membranas artificiais e naturais podem ser relacionados entre si.

Os resultados obtidos com a anfotericina B conduziram já ao estabelecimento de um modelo largamente consensual (fig. 4). Neste modelo, 0 antibiótico e o esterol associam-se "lado-alado", formando um poro que atravessa a membrana e para o interior do qual se dispõem os grupos hidroxilo da porção hidrófila do anel da anfotericina B. Este canal hidrófilo é a estrutura responsável pela acção antibiótica de lise (libertação dos constituintes citoplasmáticos) porque o seu interior é acessivel a espécies polares, sobretudo iões. No entanto, não existe qualquer modelo análogo para a filipina, que seja consensual. De entre os modelos propostos, o mais citado é o De Kruijff e Demel [7]. Estes investigadores simularam as propriedades de empacotamento das moléculas de Filipina III entre si e com o colesterol. Observaram que 0 empacotamento entre filipinas III

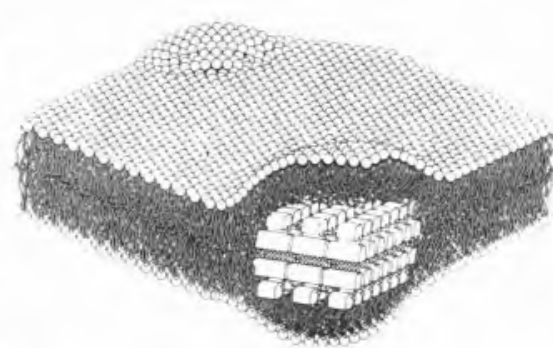

Figura 5 - Representação esquemática do agregado (filipina-colesterol) numa bicamada lipidica segundo o proposto por De Kruijff e Demel [7].

e colesterol se pode fazer por camadas paralelas (fig. 5). Uma face deste agregado plano seria hidrófoba, devido à presença dos sistemas de ligações duplas de todas as moléculas de filipina. Nestas superfícies hidrófobas, as moléculas de colesterol poderiam interactuar com a filipina e disporem-se paralelamente. Assim, poderiam também ser explicados os resultados obtidos em estudos de permeabilidade, compativeis com uma disrupção da membrana e não com a simples formação de poros. Embora deficientemente, os relevos causados por este agregados poderiam estar relacionados com algumas as formas observadas em microscopia electrónica.

Um outro modelo foi proposto por Elias et al. [8] para explicar aos seus próprios resultados, obtidos por técnicas de microscopia electrónica de crio-fractura. Nesta hipótese, que explica alguns dos relevos observados, dá-se a formação de dois grupos de quatro associações filipina/colesterol 1:1 (fig. 6), na periferia da membrana. Este modelo, altamente especulativo, é construído especialmente para prever a remoção do colesterol da interacção com as membranas.

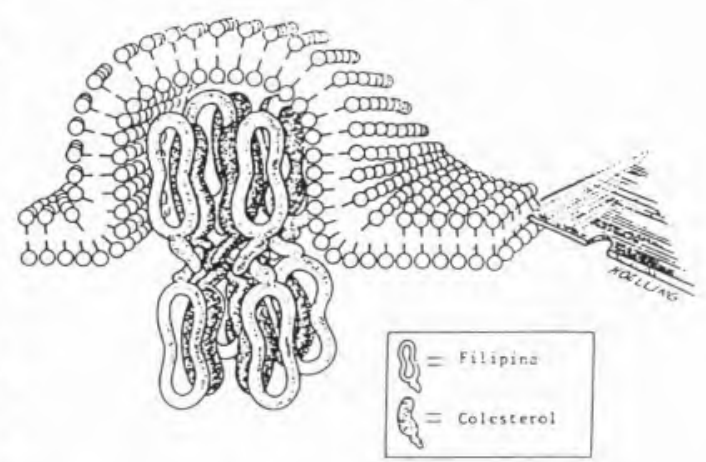

Figura 6 - Modelo especulativo da interacção filipina/colesterol em membranas lipidicas conforme o proposto por Elias et al. [8]. 
Recentemente, a «hipótese dos esteróis" foi reavaliada, demonstrandose que a filipina interactua com membranas sem esteróis (e. g. $[9,10]) .0$ carácter "tardio" desta descoberta devese à euforia gerada com a confirmação da "hipótese dos esteróis", que remeteu para o esquecimento acções paralelas da filipina. Uma produção literária fértil, logo desde que esta hipótese foi confirmada, canalizou os estudos posteriores para a interacção entre filipina e esteróis.

Milhaud [9] desenvolveu a ideia de existência de domínios de complexos filipina/fosfolípido em membranas sem esterol. Com base nas experiências efectuadas, esta autora propôs uma nova interpretação para a acção bioquímica da filipina. Segundo ela um aumento na permeabilidade das membranas pode ocorrer nas fronteiras de domínios "ordenados", correspondendo a associações filipina/fosfolípido. Ainda segundo esta proposta, o processo de segregação dos fosfolípidos em torno da filipina, com a consequente formação do mosaico tipo gel, ocorre independentemente em ambas as camadas da membrana. Logo, a abertura de um "canal" (i. e. de uma região do espaço permeável, ligando as superficies interna e externa das membranas) só ocorre quando as regiões fronteira de dois domínios (localizados em camadas diferentes) se sobrepõem (figura 7).

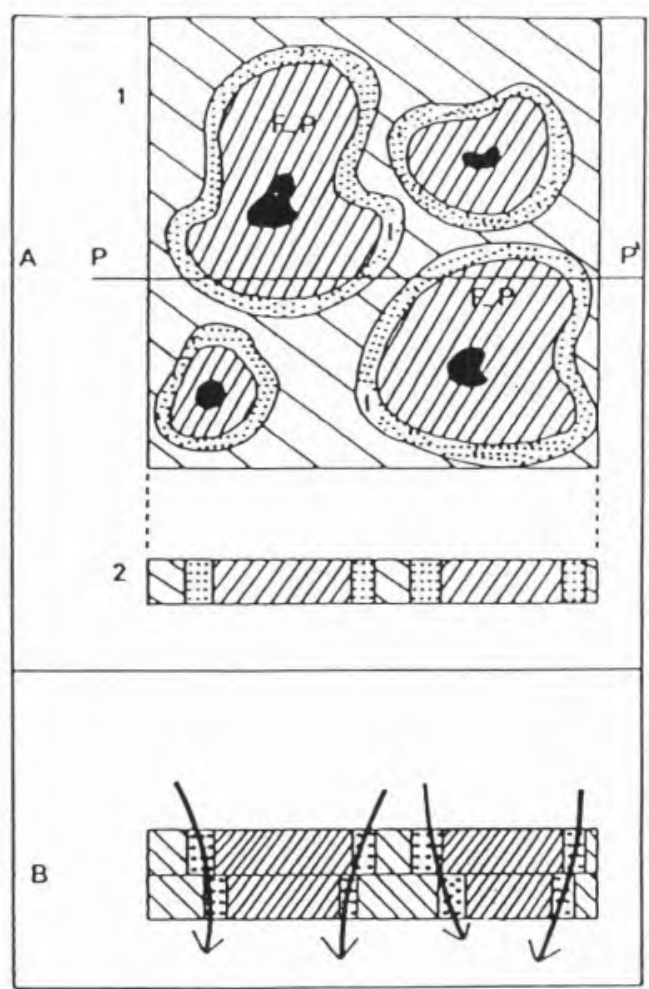

Paralelamente, a agregação da filipina em meio aquoso (fruto da sua característica anfipática, i. e. da existência de uma região hidrófila e outra hidrófoba claramente separadas) tem vindo a ser estudada na tentativa de elucidar a contribuição do estado de agregação do antibiótico para o seu mecanismo bioquímico de acção. A capacidade diferencial de interacção dos polienos antibióticos com os esteróis, dependendo do seu estado de agregação, já foi demonstrada.

Por fim, devemos notar que nos últimos anos, vários antibióticos com polieno têm sido isolados e sintetisados. 0 desenvolvimento de novas drogas tem como objectivo principal tornar os antibióticos com polieno mais eficazes sob o ponto de vista farmacêutico. Uma das características que se tenta modificar é a facilidade com que estas moléculas sofrem hidrólise ácida. Uma das consequências imediatas deste facto é impedir a administração de drogas por via oral. Além disso, os produtos da hidrólise ácida destes compostos provocam efeitos gastrointestinais não desejados.

\section{NOTAS}

1 A classificação de uma substância como antibiótico não é livre de subjectividade. É usual definir-se um antibiótico como uma substância com acção inibitória sobre 0 crescimento de microorganismos, mesmo em concentrações muito reduzidas.

${ }^{2} 0$ inverso não é verdadeiro. Por exemplo, a eritromicina é um antibiótico que é um macrólido mas não é um polieno. Curiosamente, este antibiótico tem uma acção bioquímica completamente distinta, inibindo a biossintese proteica ao nivel da subunidade $50 \mathrm{~S}$ dos ribossomas celulares.

${ }^{3}$ Segundo os autores referenciados, cerca de 40 antibióticos com polieno estariam descritos na literatura, em 1966. Em 1986 Bolard estimou em mais de duzentos o número de antibióticos com polienos já isolados, sendo dez produzidos comercialmente.

Figura 7 - a) Ilustração da configuração da organização superficial de uma camada de membrana após a acção de filipina (1 - perspectiva de topo; 2 - secção PP'; F-P, região de lípido «ordenado"; I, região fronteira). b) Corte longitudinal da bicamada com «canais abertos" [9].
${ }^{4}$ Assim chamada por ter sido isolada num extracto de microorganismos recoIhidos numa amostra do solo das Filipinas.

${ }^{5}$ Esta técnica consiste em tratar as amostras a baixa temperatura, seguindose a sua fractura em regiões e orientações seleccionadas. Destas fracturas resulta a exposição das amostras em locais antes inacessiveis.

\section{BIBLIOGRAFIA}

1. C. P. Ricardo e A. N. Teixeira (s. data) Moléculas Biológicas: Estrutura e propriedades. Didáctica Editora, Lisboa. pp. 245-277.

2. S. C. Kinsky, S. A. Luse, L. L. M. Van Deenen, Fed. Proc. 25 (1966) 1503 1510.

3. J. O. Lampen, P. M. Arnow, Z. Borowska, A. I. Laskin, J. Bacteriol. 84 (1962) 1152-1160.

4. G. Medoff, J. Brajtburg, G. S. Kobayashi, Ann. Rev. Pharmacol. Toxicol. 23 (1983) 303-330.

5. J. Bolard, Biochim. Biophys. Acta 864 (1986) 257-304.

6. N. J. Severs, H. Roebenek, Biochim. Biophys. Acta 737 (1983) 373-408.

7. B. De Kruijff, R. A. Demel, Biochim. Biophys. Acta 737 (1983) 373-408.

8. P. M. Elias, D. S. Friend, J. Goerke, J. Histochem. Cytochem. 27 (1979) 12471260.

9. J. Milhaud, Biochim. Biophys. Acta 1105 (1992) 307-318.

10. M. A. R. B. Castanho, M. J. E. Prieto, Eur. J. Biochem. 207 (1992) 125-134.

* Centro de Química Física Molecular da UTL e Faculdade de Ciências da UL 